\title{
The 2017 Nishinoshima eruption: combined analysis using Himawari-8 and multiple high-resolution satellite images
}

\author{
Takayuki Kaneko ${ }^{1 *} \mathbb{D}$, Fukashi Maeno ${ }^{1}$, Atsushi Yasuda ${ }^{1}$, Minoru Takeo ${ }^{1}$ and Kenji Takasaki ${ }^{2}$
}

\begin{abstract}
Nishinoshima volcano suddenly resumed eruptive activity in April 2017 after about 1.5 years of dormancy since its previous activity in 2013-2015. Nishinoshima is an uninhabited isolated island. We analyzed the eruption sequence and the eruptive process of the 2017 eruption (17 April-10 August: 116 days) by combining high-temporal-resolution images from Himawari-8 and high-spatial-resolution images from the ALOS-2, Landsat-8, and Pleiades satellites. We used these data to discuss how temporal variations in the lava effusion rate affected the flow formations and topographical features of the effused lava. The total effused volume was estimated to be $1.6 \times 10^{7} \mathrm{~m}^{3}$, and the average effusion rate was $1.5 \times 10^{5} \mathrm{~m}^{3} /$ day $\left(1.7 \mathrm{~m}^{3} / \mathrm{s}\right)$. Based on variations in the thermal anomalies in the $1.6-\mu \mathrm{m}$ band of Himawari-8, which roughly coincided with that of the lava effusion rate estimated by ALOS-2, the activity was segmented into five stages. In Stage 1 (17-30 April: 14 days), the lava effusion rate was the highest, and lava flowed to the west and southwest. Stage 2 (1 May-5 June: 36 days) showed a uniform decrease in flow, and lava flowed to the southwest and formed the southwestern lava delta. During Stage 3 (6-15 June: 10 days), the lava effusion rate increased in a pulsed manner, the flow direction changed from southwestward to westward, and a narrow lava flow effused from the southern slope of the cone. In Stage 4 (16 June-31 July: 46 days), the lava effusion rate decreased and lava flowed westward through lava tubes, enlarging the western lava delta. Around the end of July, lava effusion mostly stopped. Finally, in Stage 5 (1-10 August: 10 days), explosive eruptions occurred sporadically. The variation in lava effusion rate seemed to play an important role in forming different flow patterns of lava on Nishinoshima. In Stages 1 and 3, lava flowed in multiple directions, while in Stages 2 and 4, it flowed in single direction, probably because the effusion rate was lower. A pulsed increase in the lava effusion rate during Stage 3 caused new breaks and disturbances of the lava passages near the vents, which resulted in changes in flow directions. Differences in the size of lava lobes between the southwestern and western deltas are also considered to result from differences in the lava effusion rate.
\end{abstract}

Keywords: Himawari-8, LAVA FLOW, Volcano, Nishinoshima, Thermal anomaly, Remote sensing

\section{Introduction}

Nishinoshima volcano, located in the Ogasawara Islands in the western Pacific (Fig. 1a), suddenly resumed activity (Phase 2) in April 2017 after about 1.5 years of dormancy since the 2013-2015 eruption (Phase 1), which

\footnotetext{
*Correspondence: kaneko@eri.u-tokyo.ac.jp

'Earthquake Research Institute, The University of Tokyo, 1-1-1 Yayoi,

Bunkyo-ku, Tokyo 113-0032, Japan

Full list of author information is available at the end of the article
}

formed a new volcanic island (Fig. 1c). In the 2017 activity, lava effusion continued for about 4 months, and the areas from the southwest to the west of the island were covered with lava flows (Fig. 1d) (further, a small eruption occurred in 2018-Phase 3). The activities at Nishinoshima are a rare case of volcanic island formation in the ocean (Maeno et al. 2016) and furthermore are an important opportunity to observe the process of lava flowage and the eruption sequence of a volcano built up by successive layers of numerous lava flows. 

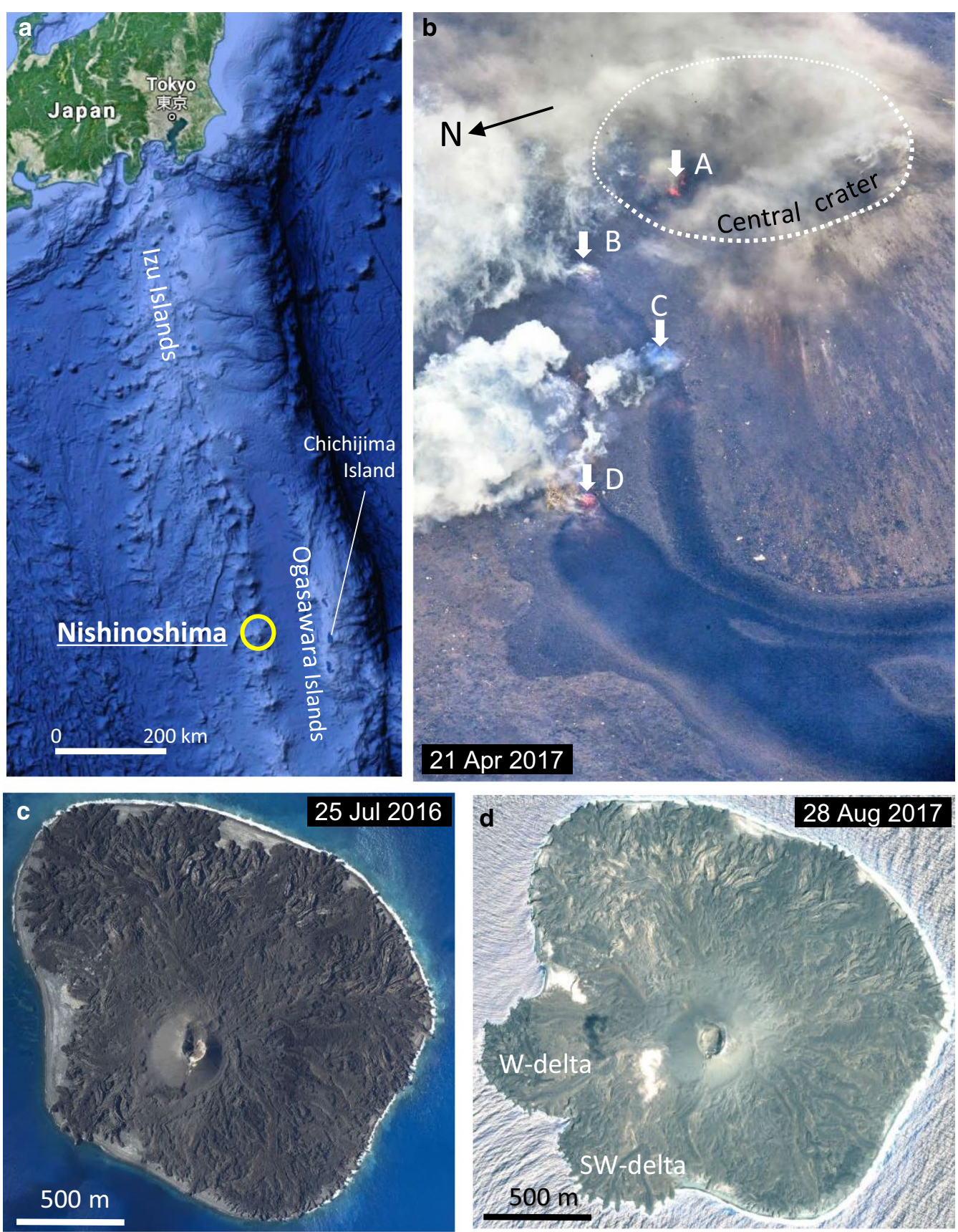

Fig. 1 a Location of Nishinoshima (reproduced from Google Maps). b Aerial view of the cinder cone and the northern vents taken from the northwestern side on 21 April 2017 (provided by Asahi Shimbun). c Nishinoshima after the 2013-2015 eruption (25 July 2016) (Geospatial Information Authority of Japan). d Pleiades image of Nishinoshima after the 2017 eruption (28 August 2017)

Unfortunately, a geological survey of the activities was difficult, as Nishinoshima is an uninhabited isolated island located $1000 \mathrm{~km}$ south of Tokyo, and $130 \mathrm{~km}$ west of the nearest inhabited island, Chichijima (Fig. 1a). During the active periods, access to areas within $4 \mathrm{~km}$ of the island was strictly prohibited.
Landing for surveying was performed once in October 2016 long after decline of the 2013-2015 activity, but it was only a 3-h stay (Takeo et al. 2018). Geophysical research was conducted by observing seismic activity with ocean-bottom seismometers installed about $4 \mathrm{~km}$ offshore from the island (Shinohara et al. 2017) and 
also by a seismometer installed in the island in October 2016 (Takeo et al. 2018), which was destroyed by the 2017 eruption. However, continuous or systematic observation of island surface activity could not be carried out, and only aerial observations and images released by governmental agencies (e.g., the Japan Coast Guard (2019) or Geospatial Information Authority of Japan (2018)) or media were available for examining the eruptive conditions. Meanwhile, Maeno et al. (2016) investigated the morphology of the lava flows effused in the first 15 months of the 2013-2015 eruption using a series of Terra SAR images, and these revealed the eruption sequence and rheological characteristics of the lava flows, which demonstrated the usefulness of satellite images for observing an isolated island in the ocean. However, the 2017 and 2018 eruptions still remain uninvestigated.

Volcanoes are widely distributed in various areas on the earth, and some of them are located in remote areas where access is difficult. Thus, remote sensing with satellites is becoming a common means of observing remote locations. Lately, the spatial and temporal resolutions of satellite images have been significantly improved compared to those available in the 1980s (e.g., Francis and Rothery 1987; Rothery et al. 1988; Glaze et al. 1989), when they were first applied to volcano observations. We have worked on developing a combined analysis for eruptive activities that uses satellite images with high temporal resolution (e.g., Himawari-8) and multiple satellites that provide images with high spatial resolution and different properties (e.g., images obtained with synthetic aperture radar (SAR), infrared images, and extremely high-spatial-resolution $(<1 \mathrm{~m})$ images). This approach has enabled us to obtain detailed information about eruption sequences and processes (Kaneko et al. 2019). The infrared image of Himawari-8 has a pixel size of $2 \mathrm{~km}$, but the observation frequency is extremely highevery $10 \mathrm{~min}$, which is suitable for capturing short-term phenomena, such as explosions, and observing long-term trends of eruptive activity with high density (Kaneko et al. 2018a). Based on the analysis of high-resolution images, we can observe detailed topographic features and the distribution of thermal anomalies of deposited materials. By combining the two kinds of information, we can investigate eruptive sequences and discern detailed variations in overall activity levels.

This study analyzed the eruption sequence and eruptive process of the 2017 Nishinoshima eruption (Phase 2) by combining the Himawari- 8 and high-resolution images from several other satellites (ALOS-2, Landsat-8, and Pleiades). Then, we determined how temporal variations in the lava effusion rate, as estimated from high-frequency observations by Himawari-8, affected the flowage and topographical features of the effused lava flows, as interpreted from the high-resolution images.

\section{Outline of the Nishinoshima activities}

The edifice of Nishinoshima volcano has a conical shape with a height of about $3000 \mathrm{~m}$ above the adjacent seafloor (Japan Coast Guard 2019). The island of Nishinoshima is the summit of this volcano that projects above the sea surface (the original Nishinoshima). The first historic eruption occurred in 1973-1974 in the ocean at a location adjacent to this island, and the edifice grew gradually and finally joined the original Nishinoshima (Aoki and Ossaka 1974; Ossaka 2004). After this activity ended, the majority of the edifice was eroded by sea waves. About 40 years later, a new activity-the 2013-2015 (Phase 1) eruption occurred at about the same place as the previous one. The eruption began in the shallow ocean in November 2013 and was followed by the subaerial effusive activity involving Strombolian eruptions. Finally, a volcanic island with a diameter of approximately $2 \mathrm{~km}$ was formed by the end of 2015 (Maeno et al. 2016, 2018) (Fig. 1c). According to Maeno et al. (2016), lava flowed down the slope and branched into several smaller lobes in a dendritic manner. The edifice grew gradually through as these lava flows piled up around the cinder cone. Lava initially flowed down as an open-channel flow, but over time as the surface solidified, flows continued through lava tubes formed below the solidified surface layer. When the lava effusion rate was high, lava flowed through large open channels with a length of several hundred meters. The average effusion rate was estimated to be about $2.0 \times 10^{5} \mathrm{~m}^{3} /$ day $\left(2.3 \mathrm{~m}^{3} / \mathrm{s}\right)$.

The 2017 Nishinoshima eruption (Phase 2) was firstly noticed on 20 April 2017 (JST) by routine observation by the Japan Coast Guard (Japan Coast Guard 2019), about 1.5 years after the end of the 2013-2015 eruption. At this time, Strombolian eruptions were occurring at the central crater of the cinder cone, and lava was effusing from several vents on the northern slope of the cone and flowed down to the west and southwest. On 24 April, the Maritime Self Defense Force confirmed that the lava flows had reached the island's coast. According to Japan Coast Guard (2019), on 27 April, the lava flows entered the sea on the west and southwest coasts. On 2 August, small-scale explosive eruptions occurred sporadically in the central crater of the cinder cone, and also weak steam emissions were recognized at front of lava flows on the west coast (Japan Coast Guard 2019). On 11 August, explosions ceased and only emission of fumarolic gas was observed.

The effused lava generally has low viscosity, and systematic differences cannot be recognized in lava flow morphology and the style of eruptive activity between the 
2013-2015 and the 2017 eruptions (Maeno et al. 2018). According to Geospatial Information Authority of Japan (2018), the cinder cone, $143 \mathrm{~m}$ high at the end of the 2013-2015 eruption, increased in height to $160 \mathrm{~m}$ during the 2017 activity. In this activity, lava deltas were formed in the southwest and west areas by effused lava (referred to as the SW-delta and W-delta, as identified in Fig. 1d).

Further, after 11 months of inactivity, an additional eruption occurred in July 2018 (Phase 3). However, this eruption was characterized by only a medium-scale lava flow near the eastern base of the cinder cone.

Figure $1 \mathrm{~b}$ shows the cinder cone as observed from the northwestern side on 21 April 2017 (JST) at the initial stage of the 2017 eruption (provided by Asahi Shimbun). A vent can be seen in the northern part of the central crater, where Strombolian activity was occurring (A in Fig. 1b). Lava flows are seen effusing from two vents on the northern slope of the cone $(B, C)$ and one vent near the base (D) (hereafter B-D are collectively referred to as "northern vents"), and flows traveled down along the western base of the cone, forming two separated flow units heading south. During the 2017 eruption, the northern vents remained as the main sources of effusing lava.

\section{Data and methods}

\section{Himawari-8 AHI}

Himawari-8 is a geostationary satellite owned by the Japan Meteorological Agency operating at a geostationary position approximately $35,800 \mathrm{~km}$ above the equator at $140.7^{\circ} \mathrm{E}$, and it entered service in July 2015 (Japan Meteorological Agency: Himawari-8/9 operational information). It has a newly developed onboard sensor, the Advanced Himawari Imager (AHI). The AHI detects 16 wavelength bands from the visible to thermal infrared regions, with a spatial resolution of $0.5-1 \mathrm{~km}$ for the visible to near-infrared bands and $2 \mathrm{~km}$ for the shortwave to thermal infrared bands. The observation frequency for full-disk images is $10 \mathrm{~min}$ (Japan Meteorological Agency: Himawari-8/9 operational information). In this study, the full-disk images obtained between April and August 2017 were downloaded from the NICT Science Cloud of the National Institute of Information and Communication Technology (http://sc-web.nict.go.jp/himaw ari/). We used the 1.6-, 2.3-, 3.9-, and 11- $\mu \mathrm{m}$ bands of the AHI for the analysis (resolution: $2 \mathrm{~km}$ ). Among these bands, $1.6 \mu \mathrm{m}$ is especially important for observing hightemperature materials, such as effusing lava. The 1.6- $\mu \mathrm{m}$ curve is highly nonlinear with increasing steepness at high temperature. This indicates that the $1.6-\mu \mathrm{m}$ band preferentially reflects thermal anomalies derived from high-temperature materials (e.g., greater than several hundred degrees Celsius), even if they occupy only small surface within the pixel (Wooster and Rothery 1997). If the temperature $\left(970-990{ }^{\circ} \mathrm{C}\right.$ in Nishinoshima, Sano et al. 2016) and the thickness of the effusing lava can be assumed to be about the same during the effusive activity, higher effusion rates of lava will increase the size of the high-temperature area and generate larger thermal anomalies in the 1.6- $\mu \mathrm{m}$ images.

In preparation of the analysis, we cut out areas consisting of $101 \times 101$ pixels with Nishinoshima at the center (approximately $200 \times 200 \mathrm{~km}$ ) from the original AHI images. In the calculations of these thermal anomalies, a $7 \times 7$ pixel region at its center was examined (Kaneko et al. 2018a). The following parameters were used to observe the time-series variations in the thermal anomalies:

$\mathrm{R} 1.6 \mathrm{Mx}$ and $\mathrm{R} 2.3 \mathrm{Mx}$ correspond to the pixel values that show the maximum spectral radiance in the $7 \times 7$ pixel region in the 1.6- and 2.3- $\mu \mathrm{m}$ images, respectively.

$\mathrm{T} 3.9 \mathrm{Mx}$ and $\mathrm{T} 11 \mathrm{Mx}$ correspond to the pixel values that show the maximum pixel-integrated temperatures in the same region in the 3.9- and 11- $\mu \mathrm{m}$ images, respectively.

In observations of an eruptive volcano from space, the spectral radiance $\left(R_{\lambda \_ \text {obs }}\right.$ in $\left.\mathrm{W} \mathrm{m} \mathrm{m}^{-2} \mathrm{~m}^{-1} \mathrm{sr}^{-1}\right)$ measured by the satellite is expressed as follows (e.g., Harris 2013):

$$
R_{\lambda_{\_} \mathrm{obs}}=\varepsilon_{\lambda} \tau_{\lambda} R_{\lambda}+R_{\lambda}^{\uparrow}+\tau_{\lambda}\left(1-\varepsilon_{\lambda}\right) R_{\lambda}^{\downarrow}+\tau_{\lambda} R_{\lambda \_ \text {ref }}+R_{\lambda_{\_} \mathrm{sl}}
$$

where $\lambda$ is the wavelength. $R_{\lambda}$ is the spectral radiance from a black body at the surface, $R_{\lambda}^{\uparrow}$ is the upwelling atmospheric radiance, $R_{\lambda}^{\downarrow}$ is the downwelling atmospheric radiance, $R_{\lambda \_ \text {ref }}$ is the sunlight reflected by the surface, $\varepsilon_{\lambda}$ is the emissivity of the radiating surface, $\tau_{\lambda}$ is the atmospheric transmittance, and $R_{\lambda_{\text {sl }}}$ is a component of the solar stray light contaminating the nighttime images (Kaneko et al. 2018b). Because geostationary satellites are on an orbit where they align in a "satellite-Earth-Sun" configuration at midnight during the vernal equinox and autumn equinox periods, the solar stray light mostly affects the nighttime images around these periods, particularly in the 1.6- and 2.3- $\mu \mathrm{m}$ bands (Kaneko et al. 2018b). On the right-hand side of Eq. (1), the first term is the thermal radiation from the surface and the third term is the component of the downwelling atmospheric radiance reflected by the surface. $R_{\lambda}$, emitted from the surface (black-body radiation) at temperature $T$ (in kelvins), is given by the Planck equation:

$$
R_{\lambda}=\frac{C_{1} \lambda^{-5}}{\pi\left[\exp \left(\frac{C_{2}}{\lambda T}\right)-1\right]}
$$


where $\quad C_{1}=3.742 \times 10^{-16} \quad \mathrm{~W} \quad \mathrm{~m}^{2}=2 \pi \mathrm{h} c^{2} \quad(\mathrm{~h} \quad$ is Planck's constant and $c$ is the speed of light) and $C_{2}=0.0144 \mathrm{~m} \mathrm{~K}=\mathrm{h} c / \mathrm{k}$ ( $\mathrm{k}$ is Boltzmann's constant).

When using nighttime images, the fourth term need not be accounted for and the second and third terms can be ignored in these wavelengths except for $R_{\lambda}^{\uparrow}$ for the $11-\mu \mathrm{m}$ band. For atmospheric correction, the atmospheric transmittance $\left(\tau_{\lambda}\right)$ was calculated assuming a model of "subtropical region/summer" with an altitude of $50 \mathrm{~m}$ using MODTRAN 3.7 (Berk et al. 1989) $(1.6 \mu \mathrm{m}$ : $0.89,2.3 \mu \mathrm{m}: 0.86,3.9 \mu \mathrm{m}: 0.84,11 \mu \mathrm{m}: 0.81$, and $R_{1 \dot{1}}^{\uparrow}$ $\left.1.25 \times 10^{6} \mathrm{~W} \mathrm{~m}^{-2} \mathrm{sr}^{-1} \mathrm{~m}^{-1}\right)$. The emissivity was assumed to be 0.95 for all bands. $R_{\lambda \_s l}$ was estimated according to the method proposed by Kaneko et al. (2018b) and corrected in the 1.6- and 2.3- $\mu \mathrm{m}$ images. Here, $R_{\lambda}$ obtained from Eq. (1) was used as the radiance value that identified volcanic thermal anomalies (equivalent to $R_{\lambda_{-} \text {vg }}$ in Kaneko et al. 2018b).

The Ogasawara Islands, including Nishinoshima, are sometimes covered by clouds throughout the year. To diminish the influence of cloud cover, a cloud test was applied using the $11-\mu \mathrm{m}$ images. The R1.6Mx, R2.3Mx, $\mathrm{T} 3.9 \mathrm{Mx}$, and $\mathrm{T} 11 \mathrm{Mx}$ having a pixel-integrated temperature in the $11-\mu \mathrm{m}$ images at the same pixel with values lower than a threshold value $(289 \mathrm{~K})$ were removed from the plots of the time-series variations. Additionally, to minimize the influence of the eruption plume or subpixel-size clouds present over the eruptive areas, we focused on the maximum values of each day to identify long-term trends of the activity (Kaneko et al. 2018a).

\section{High-resolution images}

\section{ALOS-2 PALSAR-2 images}

ALOS-2 is a land observation satellite operation by the Japanese Aerospace Exploration Agency (JAXA), and it is equipped with an L-band SAR called PALSAR-2. The ground resolution is $1 \mathrm{~m} \times 3 \mathrm{~m}$ (azimuth $\times$ range) in the highest-resolution "spotlight" mode, and it can observe the same point on the ground every 14 days (JAXA 2014). Because of SAR, it has the advantage of being able to observe regardless of weather conditions or day and night. In this study, we used the level 2.1 images (spotlight), which was orthorectified from the level 1.1 images using a digital elevation model (JAXA 2016). The image areas, including the area around Nishinoshima, were clipped from the original images and optimized for brightness and contrast before being used for interpretation.

\section{Landsat-8 OLI images}

Landsat-8 is an Earth observation satellite operated by the U.S. Geological Survey (USGS: Landsat Missions-Landsat 8), and it carries optical sensors called the Operational Land Imager (OLI) and Thermal Infrared Sensor (TIRS), which cover the visible to thermal infrared region with 11 wavelength bands. The observation cycle of the same point on the earth is 16 days. In this paper, we adopted the pixel-integrated temperature image of the 2.2- $\mu \mathrm{m}$ band of OLI (atmospheric transmittance: 1, emissivity: 1) with a resolution of $30 \mathrm{~m} \times 30 \mathrm{~m}$ to investigate the distribution of the high-temperature areas on the surface. Although the pixel-integrated temperature merely shows the apparent temperature between the minimum and maximum temperatures within a pixel (Rothery et al. 1988), the $2.2-\mu \mathrm{m}$ band is very sensitive to high- to medium-high-temperature heat sources, even if the sources occupy a small portion within a pixel, because of the nonlinearity of the $2.2-\mu \mathrm{m}$ curve between spectral radiance and temperature. Thus, the images are useful to discriminate the active areas, such as moving lava flows or erupting vents, from the background, including inactive lava flows. We used nighttime images for the analysis except the image acquired on 10 June. Landsat- 8 data used here were downloaded from the USGS distribution Web site (EarthExplorer).

\section{Pleiades image}

Pleiades is a high-resolution optical satellite operated by the French Space Agency (CNES). The resolution is $2.8 \mathrm{~m}$ for four multispectral bands and $70 \mathrm{~cm}$ for the panchromatic band (CNES: Pleiades), which can be used for interpretation of topography in detail. Here, we used a pan-sharpened image produced from merging the panchromatic band and the multispectral bands, having four spectral bands with a pixel size of $50 \mathrm{~cm}$ on the ground. We assigned the bands 4,1 , and 2 to $\mathrm{R}, \mathrm{G}$, and $\mathrm{B}$, respectively, to produce a color composite image for topographic interpretation. We used the Pleiades image taken on 28 August 2017, which was only cloud-free image relating to the 2017 eruption. As this image was taken shortly after the end of the activity, it was possible to observe the original topography of the lava lobes formed on the coast before the commencement of sea erosion.

\section{Results}

Time-series observation of thermal anomalies using Himawari-8 AHI images

\section{Analysis of activity initiation}

Himawari-8 AHI images, having high temporal resolution, are effective for accurately estimating the timing of the initiation of eruptive activity (Kaneko et al. 2018a), but cloud cover on 17-19 April prevented this. For shortterm variation, a high level of thermal anomalies continued after 11:30 on 19 April (D in Fig. 2a, b), which shows that steady lava effusion had already started at this time. Looking at the period previous to this, although a slight 


\section{a}
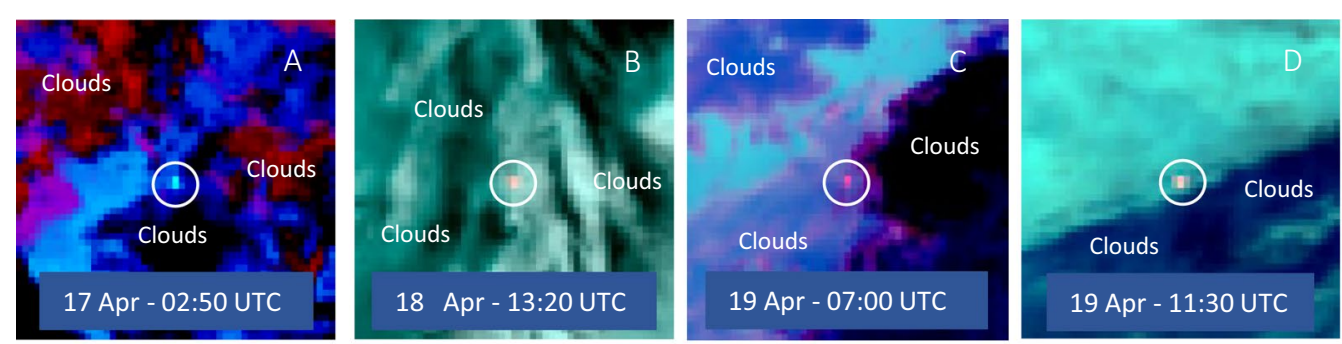

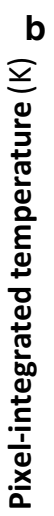

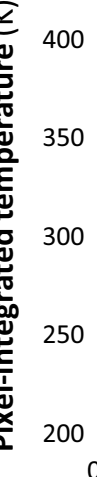

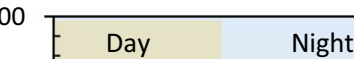

Night
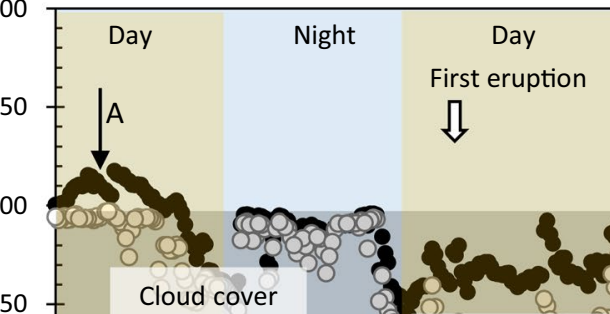

250 Cloud cover

0:0
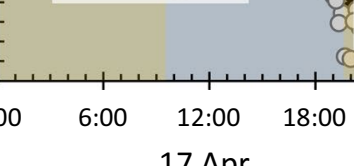

$17 \mathrm{Apr}$

Fig. 2 a Himawari-8 AHI images acquired around the start of the activity. A-D correlate with these labels in $\mathbf{b}$, and also the image collection times are marked by them in $\mathbf{b}$. $\mathbf{b}$ Time-series variation of maximum pixel-integrated temperature at 3.9 $\mu \mathrm{m}$ (T3.9Mx: closed circles) and $11 \mu \mathrm{m}$ (T11 Mx: open circles) between 17 and 19 April 2017. Arrows labeled A-D indicate the times at which the images in a were acquired

thermal anomaly is noted in the 17 April image (02:50 UTC), potentially suggesting the very initial stage of the activity (A in Fig. 2a, b), it is difficult to draw a conclusion because it is a daytime image. In the nighttime images after this date, thermal anomalies can be recognized through the clouds over Nishinoshima (B in Fig. 2a) from 13:20 to 15:30 UTC on 18 April (B in Fig. 2b). This indicates that high-temperature materials were effusing to the surface. Takeo et al. (2018) concluded that the lava effusion started at 23:05 UTC on 17 April based on the analysis of seismic data, which is consistent with the timing of appearing the thermal anomalies on 18 April.

\section{Long-term variations in thermal anomalies and establishment of activity stages}

Figure 3 shows the nighttime long-term variations of the thermal anomaly between April and August 2017 observed by Himawari-8 AHI. The 1.6- $\mu \mathrm{m}$ thermal anomaly $(\mathrm{R} 1.6 \mathrm{Mx})$ increased in a pulsed manner after 19 April and peaked on 23 April, then decreased (Fig. 3a). A moderate decreasing trend continued for over a month, and at the end of May, the level was reduced to $1 / 3$ of the first peak. However, in early June, the thermal anomaly increased in a pulsed manner again and peaked on 9 June to a level of about $2 / 3$ of the first peak. After that, a moderate decreasing trend continued for more than 1.5 months, and finally, it dropped to the background level by the end of July. As shown here, the long-term variation of thermal anomaly of the 2017 Nishinoshima eruption shows an overall decreasing trend, but it has pulsed increase in its variation at the beginning and also the middle of the activity. The thermal anomalies of the 2.3- and 3.9- $\mu \mathrm{m}$ (R2.3Mx and T3.9Mx) bands show similar variations (Fig. 3b, c).

In this study, based on the nighttime long-term variation of the 1.6- $\mu \mathrm{m}$ thermal anomaly, the 2017 Nishinoshima eruption was divided into the following five stages (Fig. 3, upper part). Because the starting time of the activity could not be precisely identified from the Himawari-8 AHI data, we assumed a time of 23:05 UTC on 17 April as the starting time of the activity (Takeo et al. 2018).

Stage 1 (17-30 April): The beginning stage of the activity when the thermal anomaly increased to a high level in a pulsed manner.

Stage 2 (1 May-5 June): The stage where the thermal anomaly showed a moderate decreasing trend following Stage 1. 


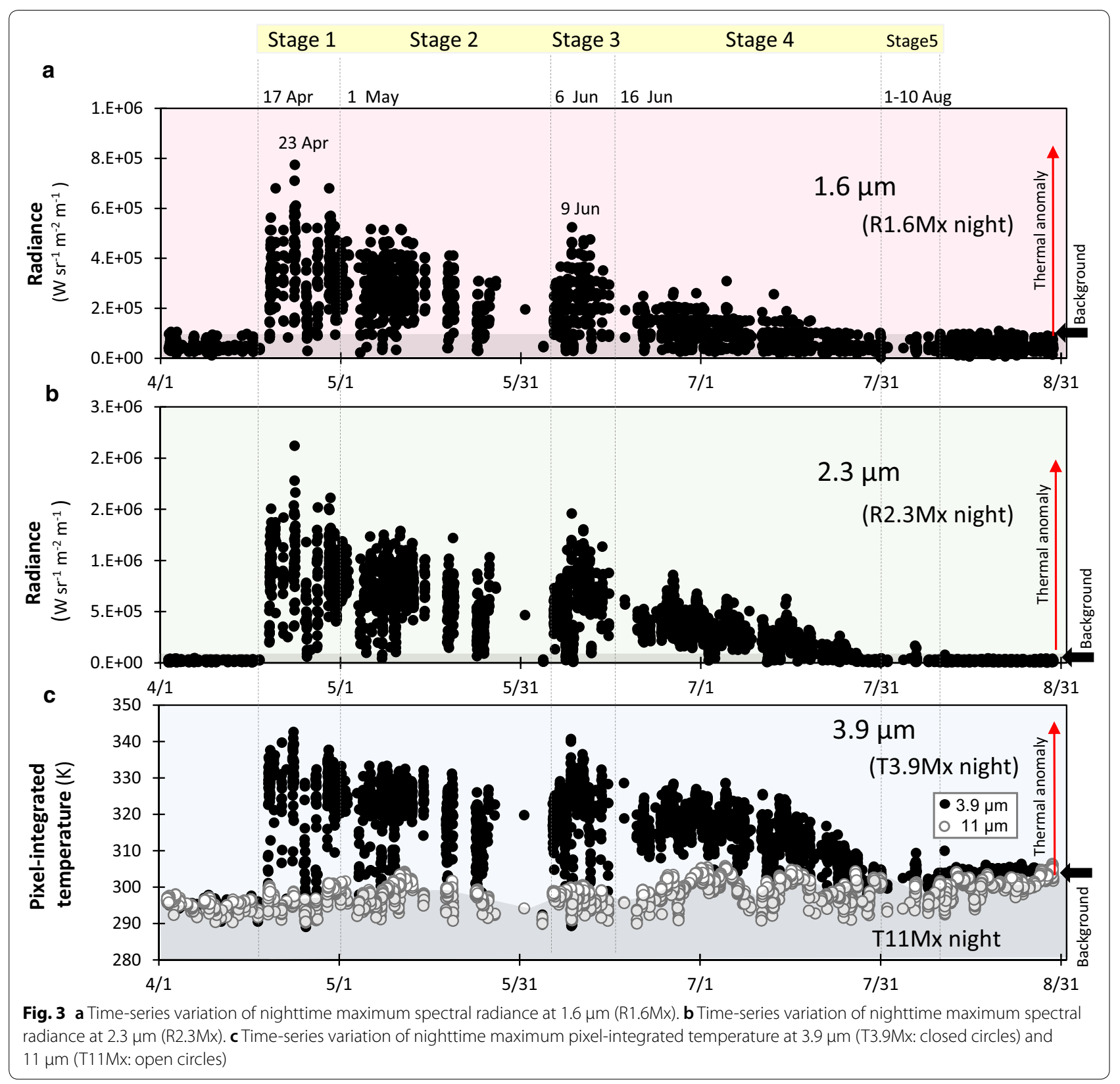

Stage 3 (6-15 June): The period when the thermal anomaly increased in a pulsed manner during the middle of the eruptive activity.

Stage 4 (16 June-31 July): The period when the thermal anomaly showed a moderate decreasing trend following Stage 3.

Stage 5 (1-10 August): The period during which the thermal anomaly returned to a background level, but small explosive eruptions occurred sporadically.

As previously described, the variation observed here is thought to reflect variations in the lava effusion rate (we discuss its relationship with the actual lava effusion rate later). The stage segmentation proposed here is also consistent with the timing of changes in the flow direction or flow mode observed in high-resolution images, as described later.

\section{Characteristics of short-term variation}

Here, we examine the characteristics of the short-term variation of thermal anomalies throughout a day with the 3.9- $\mu \mathrm{m}$ band of Himawari-8 AHI, which is relatively insensitive to reflected sunlight, using several different dates when the influence of cloud cover was negligible for 
the entire day. As shown in Fig. 4, although the thermal anomaly levels are different depending on the date, it is almost constant over $24 \mathrm{~h}$. This suggests that lava effusion was basically constant over short time scales. A similar pattern was observed in the June-August 2015 Raung eruption in Indonesia, which is thought to be characteristic of effusive eruptions of low-viscosity lava (Kaneko et al. 2018a).

\section{Eruption sequence observed by high-resolution images Interpretation of activities at each stage}

According to the stages defined by the time-series variation of thermal anomalies, the flow directions and distributions of lava flows were examined using the ALOS-2 PALSAR-2 images (Fig. 5), and also the location and state of active areas were investigated using infrared images $(2.2 \mu \mathrm{m})$ from the Landsat-8 OLI (Fig. 6). The SAR images show cumulative topographic changes since the
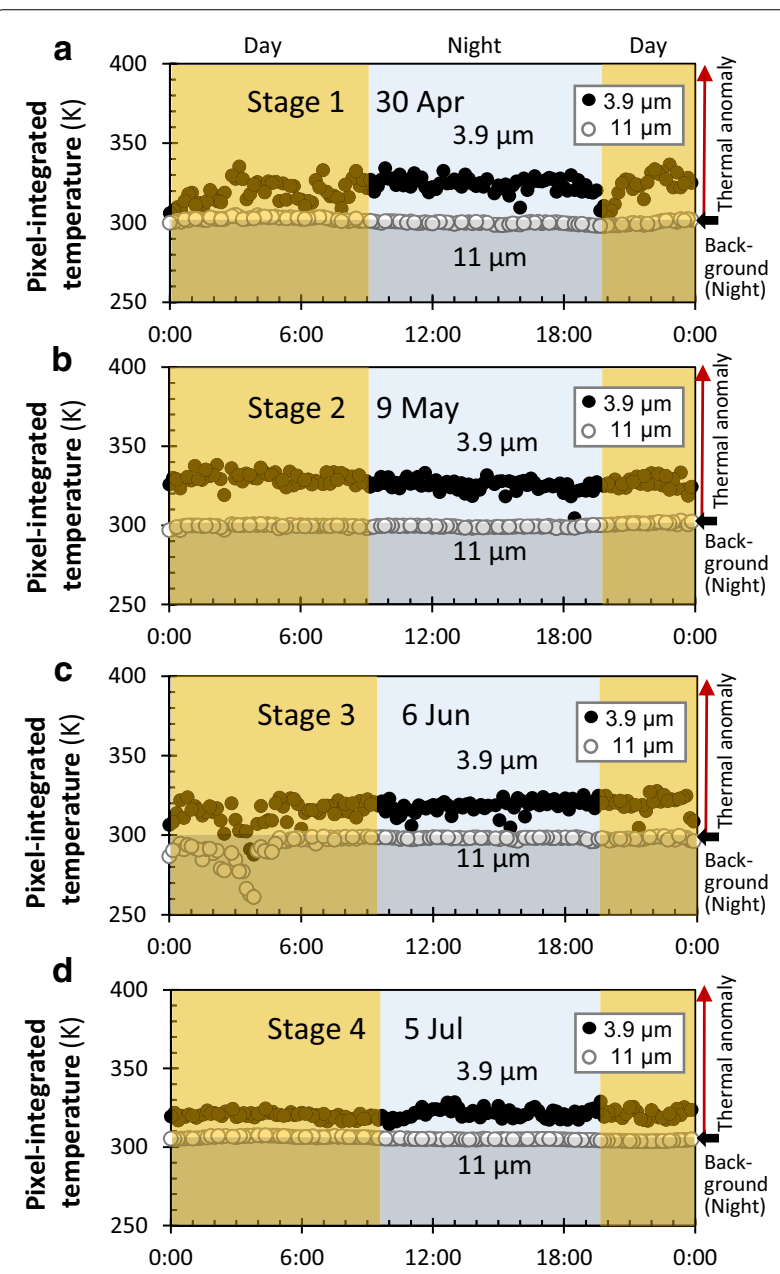

Fig. 4 Short-term variation of maximum pixel-integrated temperature at $3.9 \mu \mathrm{m}$ (T3.9Mx: closed circles) and $11 \mu \mathrm{m}$ (T11Mx: open circles) on a 30 April, b 9 May, c 6 June, and d 5 July start of the activity, while the infrared images indicate active areas at the time of observation. Using the Pleiades image (taken on 28 August 2017), we examined topographical features and the flowage process of lava flows at each stage (Fig. 7).

\section{Stage 1 (17-30 April)}

19 April (Landsat-8, Fig. 6): A high-temperature area extends westward from the northern base of the cone, and the flow tips are heading toward the west and southwest.

28 April (ALOS-2, Fig. 5): The lava flow moves westward from the northern vents and branches to the west and the southwest in the middle of the slope. The westward and southwestward flows reach the ocean at the west and southwest coasts, respectively, and they begin to form delta-like topographies there. In the Pleiades image, Stage 1 lava flows are observed in the northern half of the western region (Fig. 7a). Each flow unit branches in the middle of the slope and flows down forming several units. These are open-channel flows with levees, and they are relatively large with a width of about $30-50 \mathrm{~m}$. At the end of the 2013-2015 eruption, the central crater having a diameter of about $130 \mathrm{~m}$ (Geospatial Information Authority of Japan 2018) existed at the summit of the cinder cone, but in the ALOS-2 image, the crater is nearly buried by ejecta and a small cone is being formed inside the crater due to the Strombolian activity.

\section{Stage 2 (1 May-5 June)}

5 May (Landsat-8, Fig. 6): The cinder cone and its northwestern base show thermal anomalies. These are thought to have originated from the Strombolian activity at the summit and lava effused from the northern vents, which flowed along the western base of the cone, heading toward the southwest. The thermal anomaly extending to the southwest along the lava flow is interrupted once, and then it spreads like a fan near the coast. High-temperature areas are seen near the front of the lava flows, because in the coastal area, the lava flows spread laterally and molten lava effuses from the inside, breaking the solidified surface layer to form lobes.

12 May (ALOS-2, Fig. 5): The lava flows traveling down to the southwest are enlarging the SW-delta. Growth of the W-delta is slight. The central crater of the cinder cone generated in the previous activity has been completely buried and unified with the new cone growing inside the crater. A crater several tens of meters in diameter is generated at the top the newly formed cone.

12 May (Landsat-8, Fig. 6): The situation is almost the same as in the 5 May Landsat- 8 image. A thermal anomaly extends continuously from the upstream source to the downstream flow.

26 May (ALOS-2, Fig. 5): Growth of the SW-delta continues. Lava flows in Stage 2 are widely distributed in the 

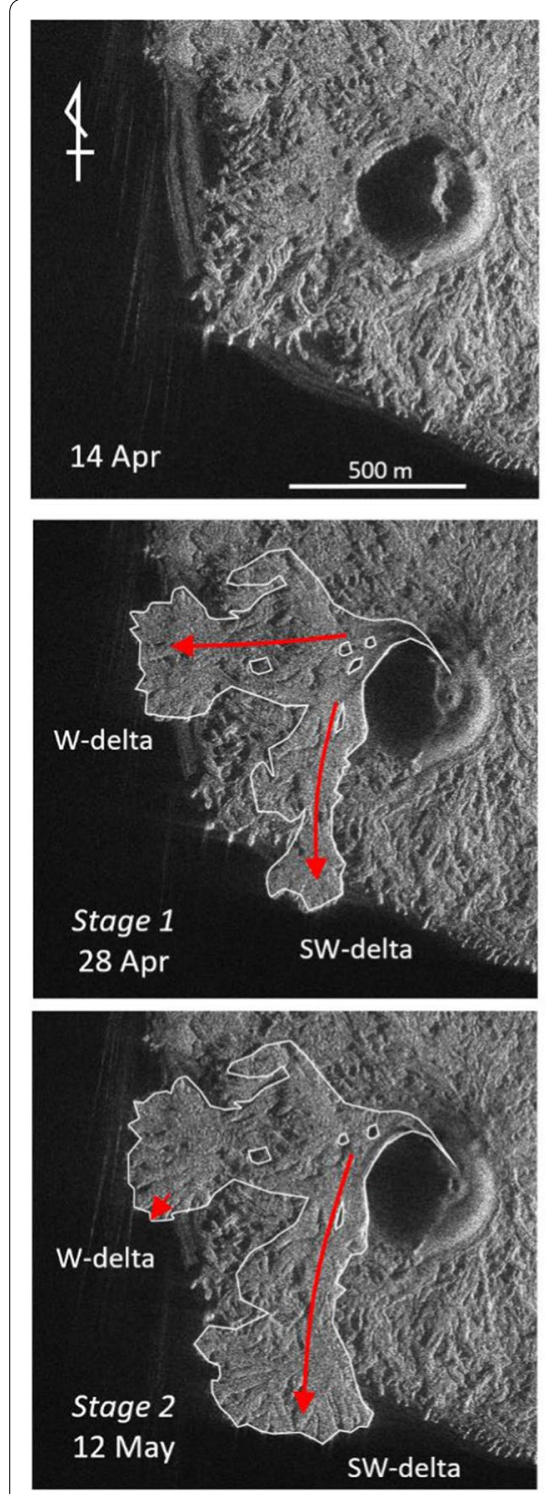
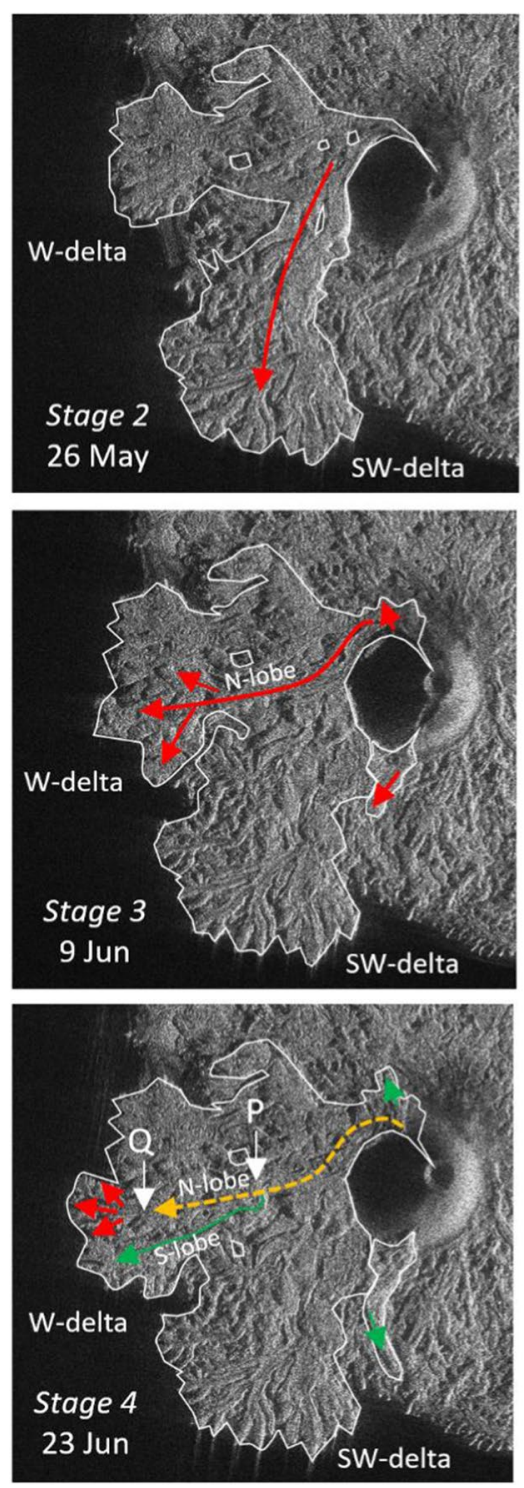
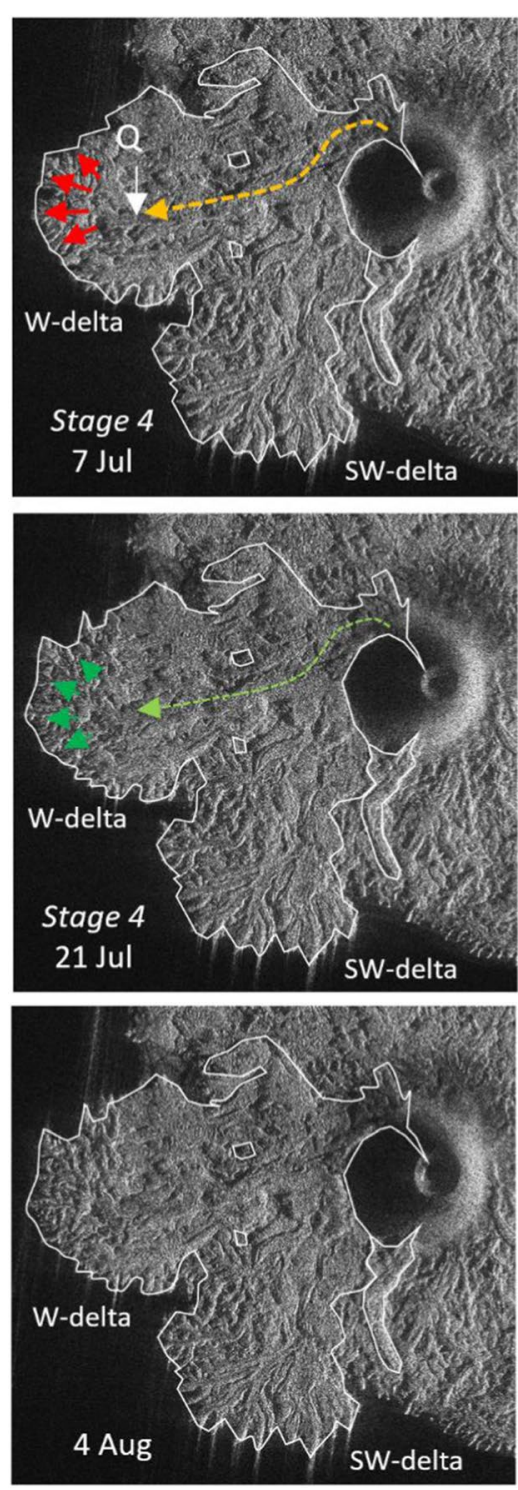

$$
\begin{aligned}
& \longleftarrow \text { Active flow (open-channel flow) } \longleftarrow \text { Nearly stopped flow (open-channel flow) } \\
& \longleftarrow-\text { Active flow (lava tube) }
\end{aligned}
$$

Fig. 5 ALOS-2 PALSAR-2 images of the southwestern part of Nishinoshima between 14 April and 4 August 2017. "P" marks an inflection point where the flow branched and changed direction, and " $Q$ " indicates an effusion point of lava from the lava tubes

southwestern areas, branching in the middle and flowing in a dendritic manner, and some parts reach up to $80 \mathrm{~m}$ in width. In the Pleiades image (Fig. 7a), it is observed that the open-channel flows are dominant in Stage 2, including the lobes forming the front part of the SWdelta (Fig. 7a, c). The W-delta is unchanged from the 12 May ALOS-2 image.

\section{Stage 3 (6-15 June)}

6 June (Landsat-8, Fig. 6): A uniformly high thermal anomaly (N-lobe) extends to the west and reaches the coast in the W-delta. In the southwestern area, except the front parts of the SW-delta, thermal anomalies cannot be observed, which suggests that the activity has almost stopped in this area.

9 June (ALOS-2, Fig. 5): A large lava flow is traveling down to the west from the northern vents and enlarging the W-delta. This unit coincides with the N-lobe in the Landsat-8 image on 6 June (Fig. 6). Also, in the Pleiades image (Fig. 7a), the N-lobe is observed on the slope as an open-channel flow with a width of 50-60 m. Enlargement 

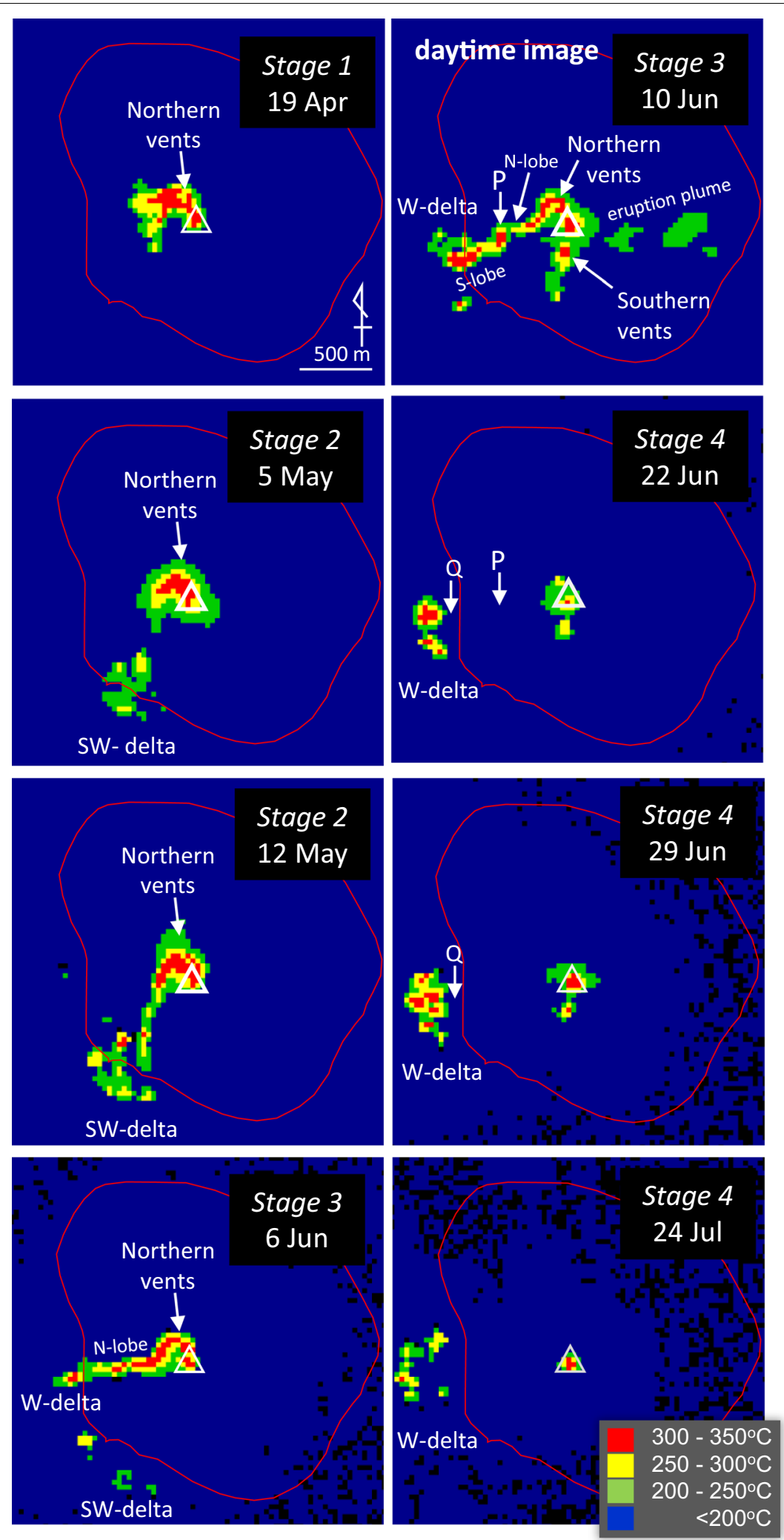

Fig. 6 Pixel-integrated temperature of the 2.2- $\mu$ m images of Landsat-8 OLI between 19 April and 24 July. These are nighttime images except for 10 June. The white triangles mark the cinder cone location 
(See figure on next page.)

Fig. 7 a Pleiades image of the southwestern part of Nishinoshima taken on 28 August 2017. Features labeled "\#1" mark deposits from the 2013-2015 eruption, and features marked "S1" to "S4" are deposits of Stages 1 to 4, respectively, from the 2017 eruption. b Close-up of the front part of the W-delta. c Close-up of the front part of the SW-delta. $\mathbf{d}$ Histogram showing the width of lobes in the W-delta. e Histogram showing the width of lobes in the SW-delta

of the SW-delta has stopped. A tiny ligulate lava flow is recognized to extend northward from the northern vents. In addition, a narrow lava flow effuses from the southern vents on the cinder cone and travels to the south. These vents are almost coincident with the ones where a smallscale lava flow effused in the 2013-2015 eruption.

10 June (Landsat-8, Fig. 6): An intense thermal anomaly is observed to extend from the northern vents to the west coast. This upstream region coincides with that seen on 6 June (N-lobe), but it has changed in the midstream region, where after it flows southward, forming inflection point " $\mathrm{P}$ " then flows westward again along the southern side of the $\mathrm{N}$-lobe in parallel (S-lobe). In the Pleiades image, it is observed that the $\mathrm{S}$-lobe flows down as an open-channel flow with a width of about $50 \mathrm{~m}$ from the vicinity of point $\mathrm{P}$ to the coast (Fig. $7 \mathrm{a}$ ). In addition, a narrow thermal anomaly extends southward from the southern slope of the cone (southern vents), which corresponds to the small lava flow observed in the ALOS-2 image (which has now nearly stopped). No lava is observed to flow to the SW-delta.

Stage 4 (16 June-31 July)

22 June (Landsat-8, Fig. 6): Small portions of the summit area and the W-delta are showing thermal anomalies, which indicates that only the W-delta is growing at this time. The thermal anomaly in the northern vents is almost invisible-these vents were likely buried by Strombolian ejecta during Stage 3, or possibly the surface was totally solidified.

23 June (ALOS-2, Fig. 5): In the two main units (N-and S-lobes) that flowed to the west in Stage 3, growth of the front part of the S-lobe has almost stopped (it enlarged around 10 June, as shown in the Landsat- 8 image in Fig. 6), while in the N-lobe, effusion occurs around point "Q" and lobes enlarge toward the coast. The narrow lava flow effused from the southern vents of the cone in Stage 3 extended to the south compared to the 9 June ALOS-2 image, but it has already stopped by the time this image was taken (this unit is inferred to have stopped moving around 10 June based on the 10 June Landsat- 8 image, Fig. 6).

7 July (ALOS-2, Fig. 5): Enlargement of the W-delta continues, although the pace is slowing down. No movement can be found in the SW-delta or other areas. In the W-delta, lava effusion continues from the tip of the $\mathrm{N}$-lobe, which forms many lobes spreading from point $\mathrm{Q}$ in a fan shape (Fig. 7a). Topographic changing relating to lava flowage on the slope cannot be recognized from the comparison between 23 June and 7 July ALOS-2 images, and also no thermal anomaly is found on the slope in Stage 4 in the Landsat- 8 images. These observations suggest that lava from the northern vents flowed down to effusing points (e.g., Q) near the coast through lava tubes without appearing on the surface. The lava tubes are thought to have been formed between Stages 3 and 4 , because the thermal anomaly observed on the slope on 10 June cannot be seen in the 22 June Landsat- 8 images.

21 July (ALOS-2, Fig. 5): The W-delta is slightly enlarged from 7 July, but lava effusion seems to have declined. The diameter of the central crater of the cone increased to about $120 \mathrm{~m}$. In the Pleiades image (Fig. 7b, c), the size of the lobes in the W-delta look systematically smaller than those in the SW-delta.

24 July (Landsat- 8 , Fig. 6): As in the Landsat-8 image on 22 June, thermal anomalies can be recognized at the cinder cone and the front parts of the W-delta, but no thermal anomalies can be seen on the slope between them. Further, in the cinder cone, the thermal anomaly is only visible at the central crater, where the Strombolian eruptions occurred, but no anomaly can be seen around the northern vents.

\section{Stage 5 (1-10 August)}

4 August (ALOS-2, Fig. 5): Very few differences in the distribution areas of lava flows are recognized between the 21 July and 4 August on ALOS-2 images. Effusive activity of lava seems to have virtually finished except for local wriggling at the flow fronts. The diameter of the central crater of the cone has increased to about $130 \mathrm{~m}$. The enlargement of the crater size in Stage 5 is thought to be related to explosive eruptions, which gained intensity close to Vulcanian (e.g., as recorded on video by the Japan Coast Guard 2019). No thermal anomaly can be recognized in the Landsat-8 image of 13 August.

\section{Estimation of effused volume and effusion rate}

The effused volume and effusion rate were estimated based on the distribution areas of the lava flows in the ALOS-2 images (Fig. 5). The subaerial volume of Nishinoshima after the end of the 2013-2015 eruption was estimated to be $8978 \times 10^{4} \mathrm{~m}^{3}$, and after the 2017 eruption, $9992 \times 10^{4} \mathrm{~m}^{3}$ (Geospatial Information Authority of Japan 2018). Using these values, the subaerial volume 


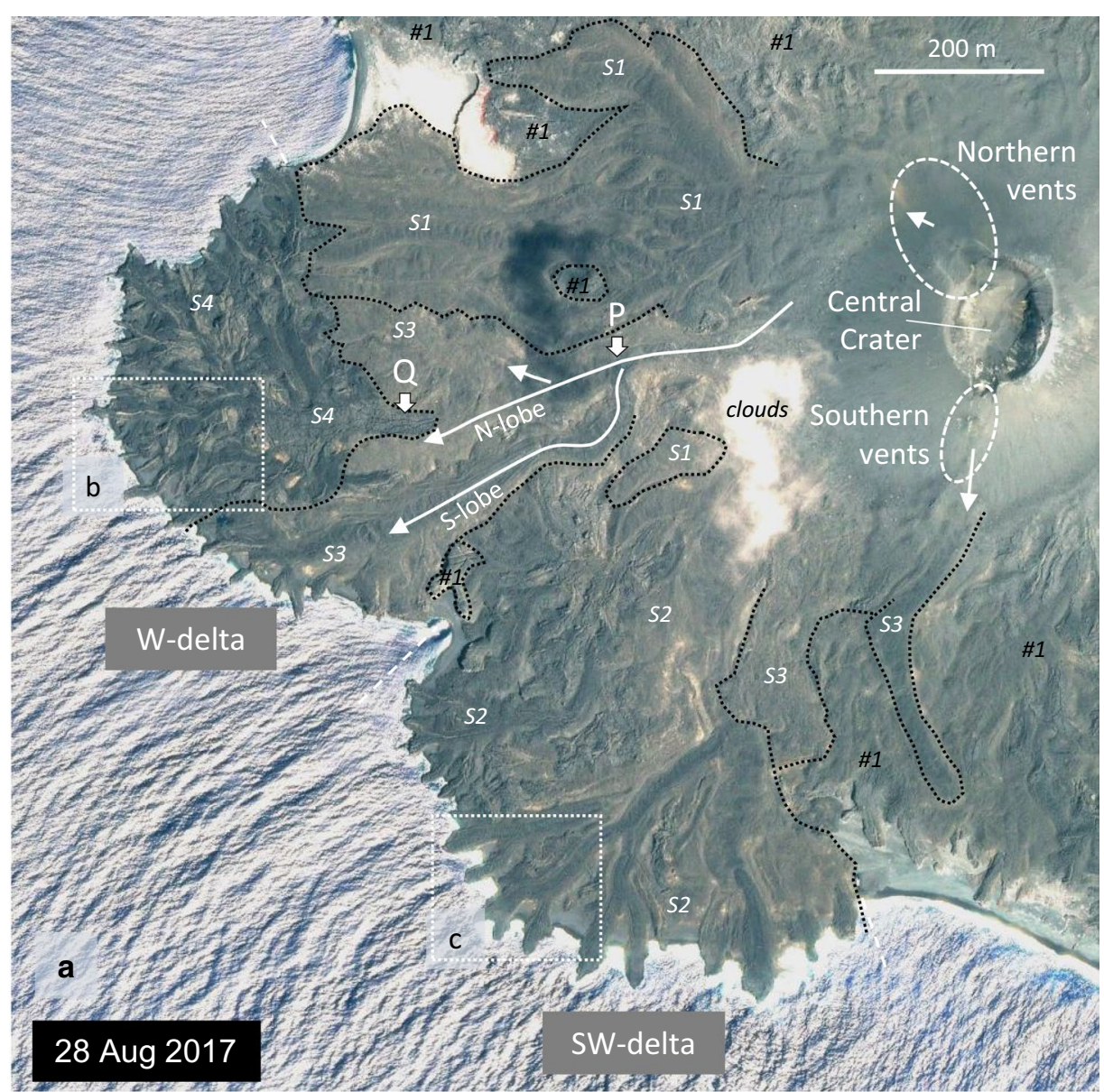

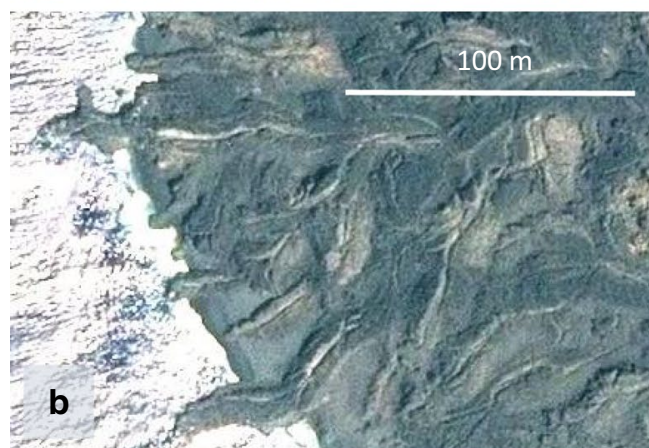

W-delta

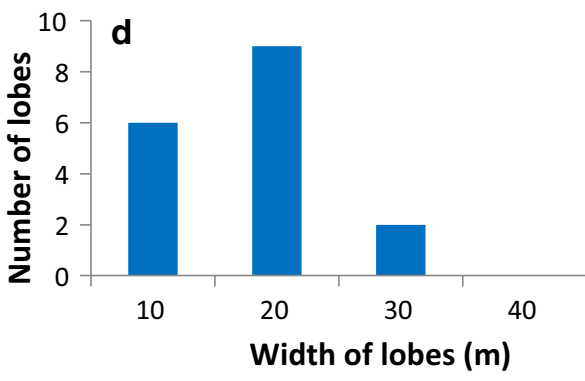

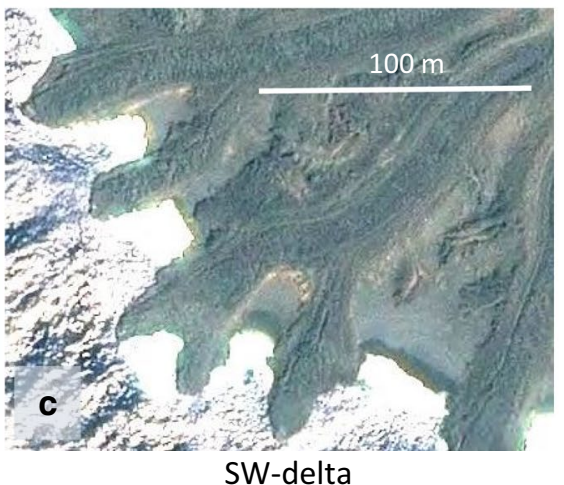

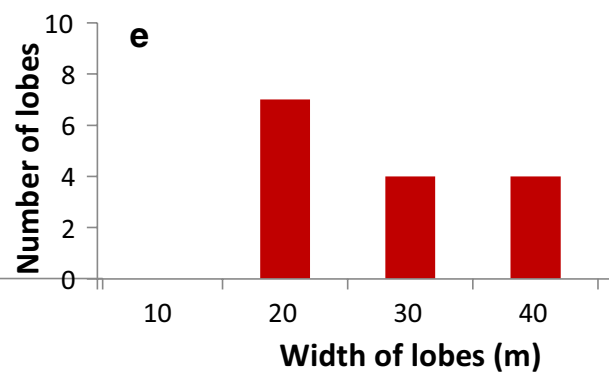


of the 2017 eruption was calculated to be $1014 \times 10^{4} \mathrm{~m}^{3}$. Within this value, the total volume of the subaerial lava and the cinder cone were inferred to occupy about $85 \%$ $\left(861.9 \times 10^{4} \mathrm{~m}^{3}\right)$ and $15 \%\left(152.1 \times 10^{4} \mathrm{~m}^{3}\right)$, respectively, by assuming that the volume is proportional to the distribution area at the final stage of the activity. The average thickness of the lava layer was calculated to be $11.7 \mathrm{~m}$ from the subaerial volume and the distribution area of the lava flow at the end of Stage $4\left(735,075 \mathrm{~m}^{2}\right)$. By assuming that the thickness of the lava layer was $11.7 \mathrm{~m}$ throughout the 2017 eruption, the subaerial lava volume of each period (usually an observation interval in the ALOS-2 images) can be calculated by multiplying this thickness and area covered by the lava flows (Fig. 8a). As for the cinder cone, the volume was once re-calculated to its dense rock equivalent (DRE) using a lava density of $2.5 \mathrm{~g} / \mathrm{cm}^{3}$ and pyroclastic material density of $1 \mathrm{~g} / \mathrm{cm}^{3}$. These volumes were allocated to each period in proportion to its durations. The volume of lava below sea level was estimated using a bathymetric chart (1:50,000 scale) made by the Japan Coast Guard shortly after the 2013-2015 eruption (Japan Coast Guard 2017). The volume was calculated for each depth zone at 10-m contour intervals using the distribution area of lava flows and the average depth in each depth zone. The subaqueous lava volume at each stage was obtained by calculating sum of all the depth zones. The subaerial and subaqueous volumes were added together to obtain the effused volume for each period. The effusion rate was obtained using the difference of the effused volume at each period. Results are shown in Table 1.

\section{Effused volume}

The total effused volume of the 2017 eruption, including the subaerial and subaqueous lava and the cone, was estimated to be $1.6 \times 10^{7} \mathrm{~m}^{3}$ (DRE). As the total effusion volume of the 2013-2015 eruption estimated by Geospatial Information Authority of Japan (2018) did not include subaqueous lava volume, the value cannot be compared with that of the 2017 eruption. In comparison with the subaerial lava volume, the effused volume of the 2017 eruption is about $10 \%$ of that in the 2013-2015 eruption. As shown in Fig. 8b, the proportion of the subaqueous lava within the total effused volume increased over time, and in late July it represented nearly $40 \%$ of the total effused volume.

\section{Effusion rate}

The average effusion rate for the 2017 eruption was calculated to be $1.5 \times 10^{5} \mathrm{~m}^{3} /$ day $\left(1.7 \mathrm{~m}^{3} / \mathrm{s}\right)$ by assuming 31 July as the termination date of lava effusion. The average effusion rate for the first 15 months of the 2013-2015 eruption was estimated to be $2.0 \times 10^{5} \mathrm{~m}^{3} /$ day $\left(2.3 \mathrm{~m}^{3} / \mathrm{s}\right)$ (Maeno et al. 2016), which indicates that the lava effusion rate of the 2017 eruption was almost equal to or slightly lower than that of the previous activity.

Figure $8 \mathrm{c}$ shows the time-series variations of lava effusion rate during the 2017 eruption. It increased to a high level during Stage 1 and gradually decreased with time in Stage 2. A gentle peak around the beginning of June in Stage 3 can be seen. After that, the effusion decreased uniformly through Stage 4 and became almost zero at the end of July.

\section{Comparison of time-series variations of the lava effusion rate and thermal anomalies}

In a previous section, we described how the time-series variation of thermal anomaly observed by the $1.6-\mu \mathrm{m}$ band of the Himawari- $8 \mathrm{AHI}$ is thought to mainly reflect that of the lava effusion rate. As shown in Fig. 8c, d, they show a similar pattern but have some differences. The major difference is that shape of the peaks is gentler in the lava effusion rate estimated from the ALOS-2 images than the rate obtained using thermal anomalies-particularly Stage 3. This is considered to result from the difference that the lava effusion rate used here is basically an average value for 14 days of observation interval of the ALOS-2 images; however, the variation based on the Himawari-8 AHI images is from instantaneous values obtained by infrared observation every $10 \mathrm{~min}$. Therefore, it is thought that the time-series variation in thermal anomalies observed by Himawari- 8 shows the pattern of lava effusion rate more accurately than that obtained from the ALOS-2 images. This indicates that in the Stages 1 and 3, the lava effusion rate increased and decreased very sharply within about 10 days, forming a pulsed pattern.

\section{Characteristic changes in lava flow according to the eruptive sequence}

The eruption sequence estimated by the combined analysis of the satellite image datasets is summarized in Fig. 9. The following major changes were recognized as the sequence of eruptive activity proceeded.

Transitions in lava flow areas: In Stages 1 and 3, which had a relatively high lava effusion rate, lava flowed in multiple directions simultaneously. In Stages 2 and 4, when the effusion rate was relatively low, lava flowed in single direction. Further, a transition in the flow direction, from southwestward to westward, occurred related to a pulsed increase in lava effusion rate in Stage 3.

Change in the flowage mode of lava flows: Lava flowed down the slope mainly as an open-channel flow in Stages 1 to 3, while in Stage 4, it was mainly transported through lava tubes from the vents to the coastal areas. 


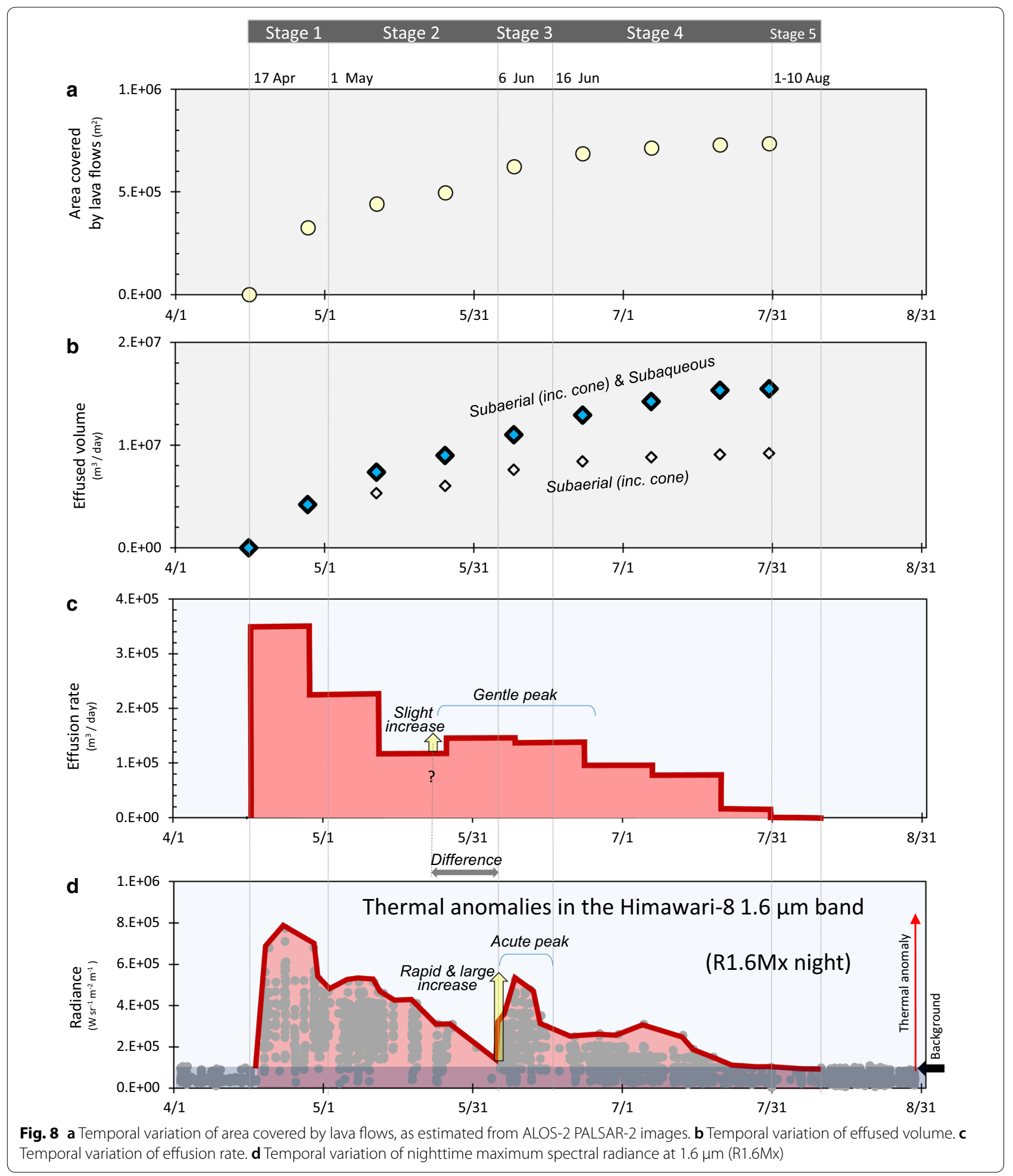

Difference in the size of lava lobes formed at the fronts of the SW- and W-deltas: Systematic differences were seen in the size and shape of the lava lobes formed at the forward sections of the lava deltas (Fig. 7b-e). The lobes formed in the SW-delta in Stage 2 are approximately 20-30 m wide and dominated by the open-channel flows. However, those formed in the W-delta in Stage 4 are approximately $10-20 \mathrm{~m}$ wide having clefts at the top. 
Table 1 Effused volume and effusion rate for the 2017 Nishinoshima eruption based on analysis of the ALOS-2 images

\begin{tabular}{|c|c|c|c|c|}
\hline Date & $\begin{array}{l}\text { Area covered by lava } \\
\text { flows } \mathrm{m}^{2}\end{array}$ & $\begin{array}{l}\text { Effused volume } \mathrm{m}^{3} \\
\text { subaerial (inc. cone) }\end{array}$ & $\begin{array}{l}\text { Effused volume } \mathrm{m}^{3} \\
\text { subaerial (inc. cone) } \\
\text { and subaqueous }\end{array}$ & Effusion rate $\mathrm{m}^{3} /$ day $\left(\mathrm{m}^{3} / \mathrm{s}\right)$ \\
\hline 28 April & 326,397 & $3,887,722$ & $4,194,931$ & 349,578 (4.05) 17-28 April \\
\hline 12 May & 441,142 & $5,310,590$ & $7,350,850$ & 225,423 (2.61) 29 April-12 May \\
\hline 26 May & 494,827 & $6,019,064$ & $8,981,191$ & 116,453 (1.35) 13-26 May \\
\hline 9 June & 623,003 & $7,599,070$ & $11,005,840$ & 144,618 (1.67) 27 May-9 June \\
\hline 23 June & 685,242 & $8,407,620$ & $12,921,828$ & 136,856 (1.58) 10-23 June \\
\hline 7 July & 713,159 & $8,814,605$ & $14,244,248$ & 94,459 (1.09) 24 June-7 July \\
\hline 21 July & 728,075 & $9,069,475$ & $15,329,851$ & 77,543 (0.90) 8-21 July \\
\hline 31 July & 735,075 & $9,208,770$ & $15,469,146$ & 13,930 (0.16) 22-31 July \\
\hline
\end{tabular}

\section{Discussion}

Lava flow fields, a collection of morphologically distinct lava flows, are often generated by continuous effusive eruptions with low-viscosity lava (Walker 1971; Self et al. 1996; Kilburn 2000; Calvari et al. 2002), as observed in the 2017 Nishinoshima eruptions. When the lava effusion rate increases, the maximum travel distance of a lava flow on a volcanic slope tends to become longer (Walker 1973; Kilburn 2000). A lava flow advance is suppressed when lava cooling at the flow front impedes further movement of the flow, even as lava effusion continues at the vent (Guest et al. 1987; Kilburn 2000; Calvari et al. 2002). This increases the internal pressure of the lava flow and may finally breach to generate an outlet, from which a major new flow can develop. This most commonly occurs somewhere along the upstream region of the flow (Kilburn 2000). Through repetition of this process, a collection of interconnected flows-lava flow fields-can be formed (Kilburn 2000). In the 2017 Nishinoshima eruption, however, the large variation of the lava effusion rate seemed more effective in causing a large breakout in the vent regions, and thus changes in the flow pattern of lava (Fig. 9), than cooling of lava at the flow front. In Nishinoshima, forward movement of lava flows was suppressed by seawater cooling near the coast, which alone did not generate a large breakout in the upstream or vent regions, probably because lava could effuse through downstream breaks, especially in the vicinity of the lava flow fronts. Details are discussed below.

\section{Relationship between transition of flow area and lava effusion rate}

In the 2017 eruption, various changes in the flow activity of lava occurred in association with the sequence of eruptive activity, that is, variation of the lava effusion rate (Fig. 9). In Stage 1, the lava effusion rate soared to a high level in a pulsed manner $\left(0\right.$ to $\sim 3.5 \times 10^{5} \mathrm{~m}^{3} /$ day: 0 to $\sim 4.0 \mathrm{~m}^{3} / \mathrm{s}$ ) at the beginning of the activity. Here, lava flowed downward both to the west and southwest, but in Stage 2, it flowed only southwestward. This is interpreted as the lava flowing down only in the direction in which it could flow easily, due to a decrease in the lava effusion rate in Stage 2. In Stage 3, a new breakout involving transitions in the lava flow area occurred; this was related to a pulsed increase in the lava effusion rate, as seen in Fig. 8c (but the change was likely much more drastic than this, considering the Himawari-8 variation seen in Fig. 8d). This is interpreted as being caused by a rapid increase in the lava effusion rate, during which lava could not drain quickly enough through the existing passages in the southwestern slope. Further, the increased internal pressure likely caused new breaches and disturbed the existing passages near the vent area, which might have changed the flow path. Therefore, the lava began to flow to the west, and at the same time, inflow of lava to the southwest path stopped. Also, new breaches were formed on the southern slope of the cinder cone to effuse a narrow lava flow to the south. In the 20132015 Nishinoshima activity, the same phenomena were observed-when the lava effusion rate increased to a high level, large-scale breakouts of lava occurred and then the flow shifted to another area (Maeno et al. 2016). In Stage 4 , lava flowed unilaterally to the west. This is thought to be caused by a decrease in the lava effusion rate between Stages 3 and 4, as it did between Stages 1 and 2. In Stage 4, lava is thought to have flowed mainly through lava tubes formed inside the Stage 3 lava flows heading west. All of the effused lava is thought to have drained to the coastal areas, because the lava effusion rate decreased to low levels. If it had increased to a level that could not be drained through the lava tubes, a new breakout would have occurred near the vents or upstream areas. 


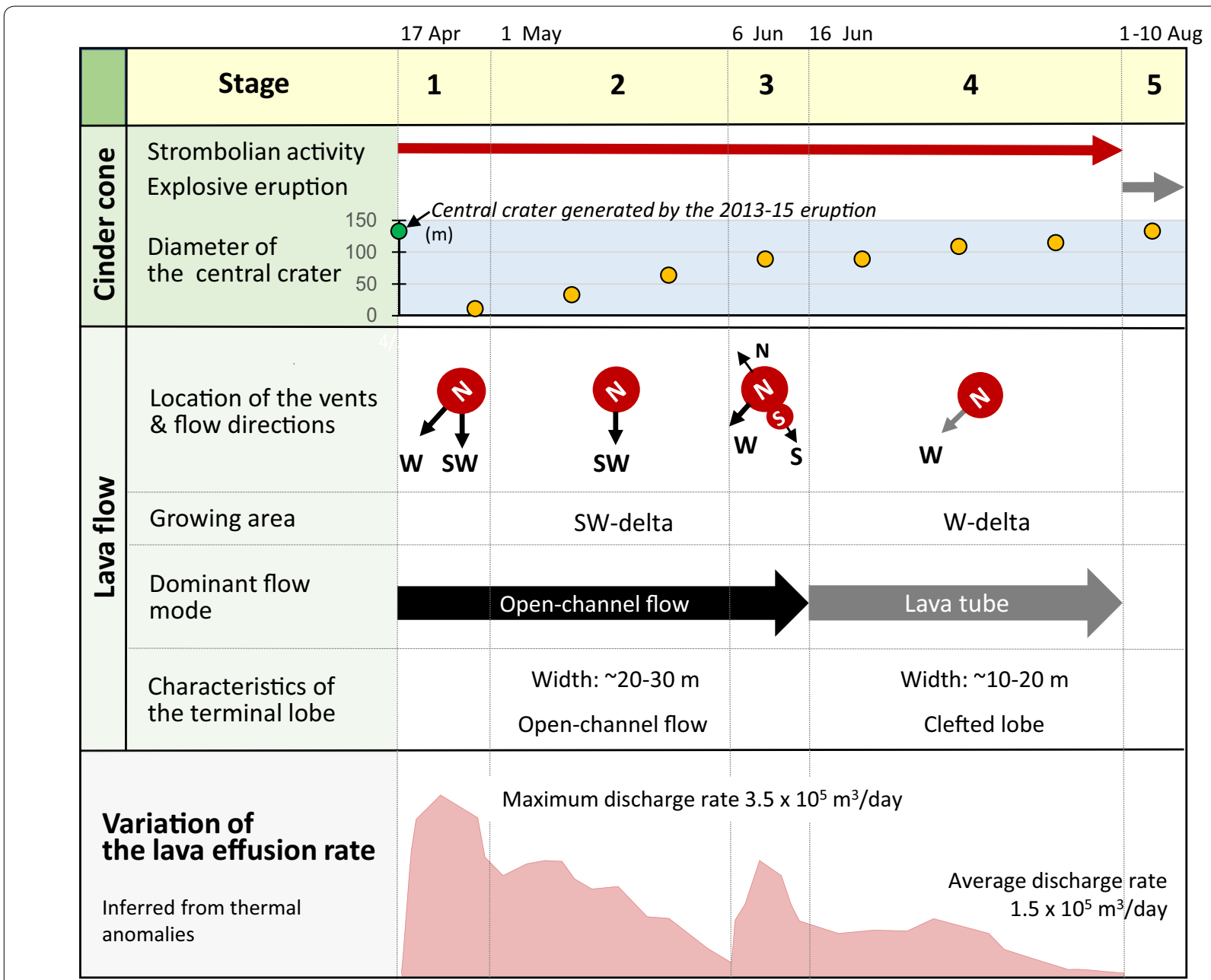

Fig. 9 Summary of the eruption sequence for the 2017 Nishinoshima eruption based on the analysis of high-frequency infrared images from the Himawari-8 AHI and high-spatial-resolution images from ALOS-2, Landsat-8, and Pleiades

\section{Possible cause of the difference in the lobe size \\ between the SW- and W-deltas}

In the Pleiades image (Fig. 7a), lava flows often branch into several lobes near the coast (e.g., at point $Q$ in the W-delta). Because lava continued to be supplied from the upstream region to the lava flow front in the coastal areas, it is inferred that lava inside the flow began to effuse by breaking through weak points of the solidified surface layer, which formed new small lobes at the front (Calvari and Pinkerton 1998). At Nishinoshima, lava flows traveled several hundred meters downstream and soon came in contact with seawater, which facilitated local solidification of the flow front and suppressed forward movement. Thus, lava effused by breaking through the upper-surficial crusts near the flow front and overflew the stiffly solidified flow front to form lobes. This might have led to the formation of many lobes in the coastal areas during this activity.
Further, in the formation of these lobes, if we can assume that when the lava effusion rate was higher, the lava supply rate to individual lobes from upstream also increased, which also increased the amount of lava effused per unit time from the breaks near the flow fronts, which in turn increased the size of the lobes generated at the front. Thus, in Stage 2, when the lava effusion rate was high, relatively large lobes were effused in the SW-delta (Fig. 7c, e). In Stage 4, when the rate was low, mostly small lobes were generated in the W-delta (Fig. 7b, d). Although the slope of the W-delta is slightly steeper than that of the SW-delta, the difference seems to exert little influence on the width of the lobes in these areas. As large lobes, 30-50 m wide are also recognized in the areas where the slope angle is about the same as the W-delta (e.g., northwestern coast). In the coastal areas on this island, the slope is sufficiently gentle, so the slight difference in the slope angle is thought to have little effect on the lobe morphology including the width. 


\section{Conclusions}

In this study, we analyzed the 2017 Nishinoshima eruption by combining high-density time-series variations of thermal anomalies from Himawari-8 AHI observations with different types of high-resolution images from ALOS-2 (SAR), Landsat OLI (infrared), and Pleiades (very high-resolution). The following results were obtained:

1. The time-series variation of effused volume and effusion rate were estimated based on the distributions of lava flows and the cinder cone size determined from the ALOS-2 images. The total effused volume, including the subaerial and subaqueous lava and the cone, was $1.6 \times 10^{7} \mathrm{~m}^{3}$ (DRE), and the average effusion rate was $1.5 \times 10^{5} \mathrm{~m}^{3} /$ day $\left(1.7 \mathrm{~m}^{3} / \mathrm{s}\right)$. The time-series variation of the thermal anomaly in the 1.6- $\mu \mathrm{m}$ band images from Himawari- 8 showed a general decreasing trend overall; however, some periods showed increases in a pulsed manner at the beginning and the middle of the activity. This pattern roughly agreed with the variation of lava effusion rate estimated from ALOS-2 images. However, the timeseries variation of the $1.6-\mu \mathrm{m}$ thermal anomalies is considered to indicate the variation more accurately than that estimated by ALOS-2, as they are instantaneous values detected by infrared observation every 10 min (for ALOS-2, the average value depended on an observation interval of 14 days).

2. Based on the characteristic of the $1.6-\mu \mathrm{m}$ band variation, the activity was segmented into five stages, as follows (Fig. 9): Stage 1: The highest lava effusion rate was observed, with lava flowing both to the west and southwest simultaneously. Stage 2: Lava effusion rate was seen to decrease uniformly, and the lava flowed to the southwest unilaterally, which increased the size of the SW-delta. Stage 3: In early June, when the lava effusion rate increased in a pulsed manner, lava effusing from the northern vents changed flow directions from southwestward to westward. At the same time, a narrow small lava flow effused from the vents on the southern slope of the cone. Stage 4: The lava effusion rate decreased and lava flowed westward through lava tubes, which developed the W-delta. Around the end of July, lava effusion mostly stopped. Stage 5: Small explosive eruptions occurred sporadically. The diameter of the central crater of the cinder cone gradually increased over time to about $130 \mathrm{~m}$ by the end of the activity.

3. Variation of lava effusion rate seemed to play an important role in the flow patterns of lava at Nishinoshima. In Stages 1 and 3, with relatively high lava effusion rates, lava flowed in multiple directions simultaneously, and in Stages 2 and 4, with a relatively low flow rate, lava flowed in single direction. This is interpreted as the lava beginning to flow down only in the direction of the easiest flow, due to a decrease in the lava effusion rate. Further, the flow directions changed after a pulsed increase in the lava effusion rate during Stage 3. Due to the rapid increase in flow, lava could not be drained sufficiently through the existing passages, and new breaks and disturbance of the passages occurred near the vent areas due to increased internal pressure; these disturbances changed the flow path. Systematic differences in the lobe size were also recognized between the SW-delta ( 20-30 m wide) and W-delta ( 10-20 m wide). This is also considered to result from a decrease in the lava effusion rate, which led to the formation of smaller lobes.

4. Lava flowed mainly through open channels in Stages 1 to 3 and through lava tubes in Stage 4. This is considered to be due to progression of surface cooling over time as the lava effusion rate decreased, which encouraged the formation of lava tubes in Stage 4. The decrease in effusion rate, but especially a steady value of effusion rate, normally promotes the formation of lava tubes (Calvari and Pinkerton 1998).

5. The lava effusion rate was inferred to be almost constant over short timescales, because the observed thermal anomalies were nearly constant over 24-h periods. This property seems to be a common characteristic for effusive eruptions by low-viscosity lava, as at Nishinoshima.

\section{Acknowledgements}

The Landsat- 8 OLI images used here were provided by the USGS. The ALOS-2 images were provided by JAXA/EORC. The Himawari-8 AHI data used in this study were received by the Meteorological Research Center of the Japan Meteorological Agency and processed and managed by K. Murata of NICT. We thank H. Murakami of JAXA/FORC and Y. Honda and K. Kajiwara of the Center for Environmental Remote Sensing, Chiba University, for their encouragement and helpful suggestions. Comments and suggestions from S. Calvari and an anonymous reviewer were greatly helpful for improving the manuscript.

\section{Authors' contributions}

$T K, A Y$, and $K T$ analyzed the satellite images, and FM and MT examined the eruptive activity. All authors read and approved the final manuscript.

\section{Funding}

This work was supported by a Grant-in-Aid for Scientific Research from the Japan Society for the Promotion of Science, Kakenhi C Grant No. 19 K04011 to TK and A Grant No. 16H02221 to MT; second Research Announcement on the Earth Observations (PI No. ER2GCF111 to TK) from the Earth Observation Research Center of Japan Aerospace Exploration Agency (JAXA/EORC); Earthquake and Volcano Hazards Observation and Research Program of the Ministry of Education, Culture, Sports, Science and Technology of Japan (No. 1520); and Cross-ministerial Strategic Innovation Promotion Program II - SIP II (Enhancement of Societal Resiliency against Natural Disasters).

Availability of data and materials Not applicable. 


\section{Competing interests}

The authors declare that they have no competing interests.

\section{Author details}

${ }^{1}$ Earthquake Research Institute, The University of Tokyo, 1-1-1 Yayoi, Bunkyo-ku, Tokyo 113-0032, Japan. ${ }^{2}$ Japan Fisheries Research and Education Agency, 2-12-4 Fukuura, Kanazawa, Yokohama, Kanagawa 236-8648, Japan.

Received: 4 October 2019 Accepted: 9 December 2019

Published online: 19 December 2019

\section{References}

Aoki H, Ossaka J (1974) Mistry of a submarine volcano-record of landing and survey of Nishinoshima. Tokai Univ Press, Kanagawa, Japan, p 250. (in Japanese)

Berk A, Berstein S, Robertson DC (1989) MODTRAN: a medium resolution model LOWTRAN-7. Tech Rep, GL-TR-89-0122, Geophys Lab, Hanscom AFB, MA

Calvari S, Pinkerton H (1998) Formation of lava tubes and extensive flow field during the 1991-1993 eruption of Mount Etna. J Geophys Res 103:27291-27301

Calvari S, Neri M, Pinkerton H (2002) Effusion rate estimations during the 1999 summit eruption on Mount Etna, and growth of two distinct lava flow fields. JVolcanol Geotherm Res 119:107-123. https://doi.org/10.1016/ S0377-0273(02)00308-6

CNES: Pleiades. https://pleiades.cnes.fr/en/pleiades/glance/home. Accessed 27 Sept 2019

EarthExplorer. https://earthexplorer.usgs.gov/. Accessed 27 Sept 2019

Francis PW, Rothery DA (1987) Using the Landsat thematic mapper to detect and monitor active volcanoes: an example from Lascar volcano, northern Chile. Geology 15:614-617

Geospatial Information Authority of Japan (2018) Latest observation results on Nishinoshima (as of January 2018). http://www.gsi.go.jp/kanri/kanri41009 .html. (in Japanese). Accessed 27 Sept 2019

Glaze L, Francis PW, Rothery DA (1989) Measuring thermal budgets of active volcanoes by satellite remote sensing. Nature 338:144-146

Guest JE, Kilburn CRJ, Pinkerton H, Duncan AM (1987) The evolution of lava flow-fields: observations of the 1981 and 1983 eruptions of Mount Etna, Sicily. Bull Volcanol 49:527-540. https://doi.org/10.1007/BF01080447

Harris AJL (2013) Thermal remote sensing of active volcanoes, a user's manual. Cambridge University Press, UK

Japan Coast Guard (2017) Bathymetric Chart: No $6556^{8}$ NISHI-NO-SHIMA

Japan Coast Guard (2019) Nishinoshima. https://www1.kaiho.mlit.go.jp/GIJUT SUKOKUSAI/kaiikiDB/kaiyo18-e1.htm. Accessed 27 Sept 2019

Japan Meteorological Agency: Himawari-8/9 operational information. http:// www.data.jma.go.jp/mscweb/en/operation8/. Accessed 27 Sept 2019

JAXA (2014) Advanced Land Observing Satellite-2(ALOS-2)DAICHI-2. http:// www.jaxa.jp/projects/sat/alos2/. Accessed 27 Sept 2019

JAXA (2016) PALSAR-2 Level 1.1/2.1/1.5/3.1CEOS SAR Product Format Description. https://www.eorc.jaxa.jp/ALOS-2/en/doc/format.htm. Accessed 27 Sept 2019

Kaneko T, Takasaki K, Maeno F, Wooster MJ, Yasuda A (2018a) Himawari-8 infrared observations of the June-August Mt. Raung eruption, Indonesia. Earth Planets Space 70:89. https://doi.org/10.1186/s40623-018-0858-9

Kaneko T, Yasuda A, Yoshizaki Y, Takasaki K, Honda Y (2018b) Pseudo thermal anomalies in the shortwave infrared bands of the Himawari-8 $\mathrm{AHI}$ and their correction for volcano thermal observation. Earth Planets Space 70:175. https://doi.org/10.1186/s40623-018-0858-9
Kaneko T, Maeno F, Yasuda A (2019) Observation of the eruption sequence and formation process of a temporary lava lake during the June-August 2015 Mt. Raung eruption, Indonesia, using high-resolution and high-frequency satellite image datasets. J Volcanol Geotherm Res 377:17-32. https://doi. org/10.1016/j.jvolgeores.2019.03.016

Kilburn CRJ (2000) Lava flows and flow fields. In: Sigurdsson H (ed) Encyclopedia of Volcanoes. Academic Press, San Diego, pp 291-306

Maeno F, Nakada S, Kaneko T (2016) Morphological evolution of a new volcanic islet sustained by compound lava flows. Geology 44(4):259-262. https://doi.org/10.1130/G37461.1

Maeno F, Yasuda A, Nakano S, Yoshimoto M, Ohminato T, Watanabe A, Kaneko T, Nakada S, Takeo M (2018) Formation process of a new volcanic island at Nishinoshima, Ogasawara, Japan, inferred from eruptive products. J Adv Mar Sci Technol Soc 24:35-44 (in Japanese with English abstract)

Ossaka J (2004) A story about survey of submarine volcanoes (5). Suiro 32:34-39 (in Japanese)

Rothery DA, Francis PW, Wood CA (1988) Volcano monitoring using short wavelength infrared data from satellites. J Geophys Res 93:7993-8008

Sano T, Shirao M, Tani K, Tsutsumi Y, Kiyokawa S, Fujii T (2016) Progressive enrichment of arc magmas caused by the subduction of seamounts under Nishinoshima volcano, Izu-Bonin Arc, Japan. J Volcanol Geotherm Res 319:52-65

Self S, Thordarson Th, Keszthelyi L, Walker GPL, Hon K, Murphy MT, Long P, Finnemore S (1996) A new model for the emplacement of Columbia River basalts as large, inflated Pahoehoe lava flow fields. Geophys Res Lett 23:2689-2692. https://doi.org/10.1029/96GL02450

Shinohara M, Ichihara M, Sakai S, Yamada T, Takeo M, Sugioka H, Nagaoka Y, Takagi A, Morishita T, Ono T, Nishizawa A (2017) Continuous seismic monitoring of Nishinoshima volcano, Izu-Ogasawara, by using long-term ocean bottom seismometers. Earth Planets Space 69:159. https://doi. org/10.1186/s40623-017-0747-7

Takeo M, Ohminato T, Maeno F, Shinohara M, Baba K, Watanabe A, Ichihara M, Nishida K, Kaneko T, Yasuda A, Sugioka H, Hamano Y, Tada N, Nakano S, Yoshimoto M, Takagi A, Nagaoka Y (2018) Geophysical observations and landing survey at Nishinoshima volcano. J Adv Mar Sci Technol Soc 24:45-56 (in Japanese with English abstract)

USGS: Landsat Missions_Landsat 8. https://www.usgs.gov/land-resources/ nli/landsat/landsat-8?qt-science_support_page_related_con=0\#qt-scien ce_support_page_related_con. Accessed 27 Sept 2019

Walker GPL (1971) Compound and simple lava flows and flood basalts. Bull Volcanol 35:579-590. https://doi.org/10.1007/BF02596829

Walker GPL (1973) Lengths of lava flows [and Discussion]. Phil Trans R Soc Lond A 274:107-118

Wooster MJ, Rothery DA (1997) Thermal monitoring of Lascar volcano, Chile, using infrared data from the along-track scanning radiometer: a 1992-1995 time series. Bull Volcanol 58:566-579

\section{Publisher's Note}

Springer Nature remains neutral with regard to jurisdictional claims in published maps and institutional affiliations.

\section{Submit your manuscript to a SpringerOpen ${ }^{\circ}$ journal and benefit from:}

- Convenient online submission

- Rigorous peer review

- Open access: articles freely available online

- High visibility within the field

Retaining the copyright to your article

Submit your next manuscript at springeropen.com 